\title{
Argon plasma coagulation of the papilla of Vater for treatment of a Dieulafoy lesion
}

A 54-year-old man was admitted to the emergency room for a syncope episode and melena. The laboratory test highlighted a hemoglobin of $6.8 \mathrm{~g} / \mathrm{dL}$, and 2 blood transfusions were performed. An upper endoscopy revealed stigmata of recent bleeding in the duodenum, and active bleeding was visualized at the level of the major papilla. Therefore, hemobilia or hemosuccus pancreaticus was suspected. An abdominal computed tomography (CT) scan did not reveal any underlying biliopancreatic disorder.

The patient was referred to our center for a duodenoscopy. Duodenal exploration confirmed active oozing from the papilla of Vater. A small Dieulafoy lesion was detected at the roof of the major papilla ( $\vee$ Video 1$)$. Hemostasis was required, however; and owing to a potential risk of post-procedural pancreatitis, a 5-Fr plastic stent was deployed within the main pancreatic duct without prior sphincterotomy. Several hemostatic techniques were evaluated, namely band ligation, clips, and argon plasma coagulation (APC). The first two approaches were rejected in order to avoid permanent closure of the papillary orifices, whereas APC (forced, effect 2, 60 watts) allowed immediate hemostasis ( Video 1 ). The patient was observed and discharged at post-procedural day 4 . At the 15-day follow-up, the endoscopy showed complete healing of the papilla of Vater and the spontaneous migration of the pancreatic stent.

Dieulafoy's lesions have been reported throughout the digestive tract, with a higher prevalence in the stomach and the duodenum [1]. We report a rare case of a Dieulafoy lesion of the major papilla successfully treated with APC.

Different from other authors [2], we deployed a prophylactic pancreatic plastic stent to prevent post-procedural pancreatitis. Although it is a rare adverse

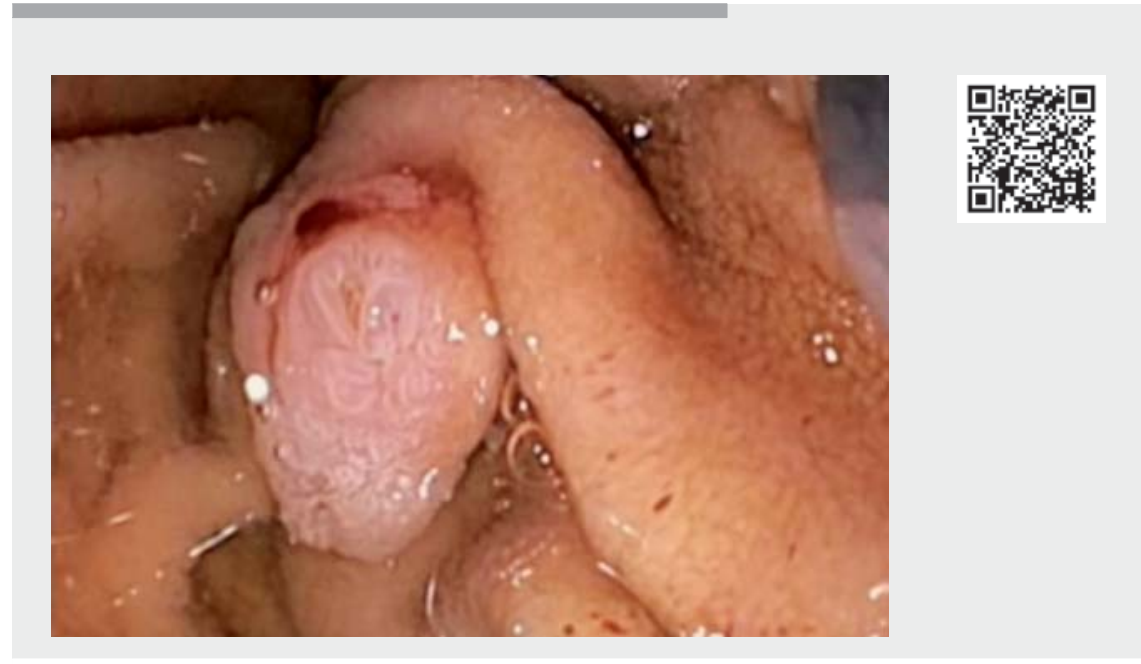

Video 1 Endoscopic treatment of a Dieulafoy lesion of the major papilla with argon plasma coagulation and prophylactic pancreatic stent deployment.

event, we believe it is important to adopt all the viable approaches to minimize its occurrence, especially in a frail hemorrhagic patient. We believe that in the near future it will be of utmost importance to equip every unit performing emergency endoscopy with a disposable duodenoscope.

Endoscopy_UCTN_Code_TTT_1AO_2AD

\section{Competing interests}

The authors declare that they have no conflict of interest.

\section{The authors}

\section{Gianfranco Donatelli ${ }^{1}$, Fabrizio Cereatti ${ }^{1}$, Ilva} Lodolo², Tullio Piardi ${ }^{3}$

1 Unité d'Endoscopie Interventionnelle, Hôpital Privé des Peupliers, Paris, France

2 Service de Gastroenterologie, Hôpital Simon Veil, Troyes, France

3 Service de Chirurgie, Hôpital Simon Veil, Troyes, France

\section{Corresponding author}

Gianfranco Donatelli, MD

Hôpital Privé des Peupliers, Générale de Santé, Unité d'Endoscopie Thérapeutique, 8 Place de l'Abbé G. Hénocque, Paris 75013 , France

donatelligianfranco@gmail.com

\section{References}

[1] Baxter M, Aly EH. Dieulafoy's lesion: current trends in diagnosis and management. Ann $\mathrm{R}$ Coll Surg Engl 2010; 92: 548-554

[2] Han S, Wagh MS, Wani S. The rare finding of a Dieulafoy's lesion at the major papilla. Endoscopy 2021; 53: E44-E45

\section{Bibliography}

Endoscopy 2022; 54: E153

DOI $10.1055 / a-1471-2313$

ISSN 0013-726X

published online 28.4.2021

(c) 2021. Thieme. All rights reserved.

Georg Thieme Verlag KG, Rüdigerstraße 14, 70469 Stuttgart, Germany 